\section{Call for further study of alleged leukaemia link - Wider study advised - Proposed mechanism doubted} London

The UK Committee on Medical Aspects of Radiation in the Environment (COMARE) has advised the Department of Health (DoH) that further study is needed of the link between childhood leukaemia in the village of Seascale, West Cumbria, and the fathers' exposure to radiation at the Sellafield nuclear reprocessing plant. The link was suggested by Martin Gardner and his colleagues from the University of Southampton in a controversial report released last month (see Nature 343, 679; 22 February 1990).

Immediately after its release, the Gardner report was referred for "urgent consideration" to COMARE, an independent scientific group that advises the government. COMARE is chaired by Professor Martin Bobrow of Guy's and St Thomas's Hospitals, London.

COMARE says that similar studies, looking at leukaemia clusters around other nuclear sites at Dounreay in Scotland, and Aldermaston and Burghfield in southern England, should be completed "as soon as possible". A new search is also needed for links between other British radiation workers' radiation exposure and national records of childhood cancer.

COMARE accepts the validity of the methods used by Gardner and his colleagues but notes that the conclusions are based on very few cases and do not prove a causal effect. The same conclusion was reached by epidemiologists asked to review the Gardner report by British Nuclear Fuels Limited, the site operators at Sellafield (see Nature 344, 283; 22 March 1990). Research is now needed to identify an underlying mechanism - before this is better understood, COMARE says, it cannot make any detailed recommendations on how best to protect radiation workers.

Gardner's team suggest, that radiation damage to the DNA of sperm cells may be to blame. But many radiation scientists are sceptical, particularly those who found no leukaemia excess among the children of the Japanese atomic bomb survivors.

An article in the latest issue of the pronuclear newsletter Nuclear Issues by John Fremlin, emeritus professor at the University of Birmingham, questions the evidence cited by Gardner to support his theory. Fremlin points out that the level of radiation used in a Japanese study that showed irradiated male mice sired offspring prone to develop cancer was far

higher than that received by workers at Sellafield. Irradiation produced a range of cancers, mostly in the lungs.

Uncovering the mechanism responsible for the 'Gardner effect' will need some basic biological research, but COMARE also wants more studies on the Sellafield workers: some epidemiologists suggest that exposure to chemicals, or the internal radiation dose (the amount of radioactivity actually concentrated in the workers' body tissues, rather than the 'external' doses measured from workers' film badges) could explain the results.

Another important issue is which of the two doses linked by Gardner to the leukaemia cases (a lifetime dose of more than 100 milliSieverts, or more than $10 \mathrm{mSv}$ in the six months before conception), is the more significant. The apparent contradiction between Gardner's results and the low leukaemia incidence in the children of atom bomb survivors could be explained NUCLEAR WASTE

\section{Boston}

ONE of the more bizarre problems surrounding the construction of the US nuclear waste repository in the salt beds at Carlsbad, New Mexico, was brought up last month at a meeting of the National Academy of Science (NAS) panel that is overseeing the project.

There it was pointed out that if federal regulations are to be strictly observed, then the site should be protected from human intruders for the next 10,000 years. But who knows what human society will be like in 10,000 years? Rip Anderson, a manager at Sandia National Laboratory who supervises WIPP's performance schedule for the Energy Department, is one of several officials who has to take this issue seriously. $\mathrm{He}$ says he will convene a working group next month and invite linguists and archaeologists to help. Preliminary discussion will focus on what kind of markers might still be effective far into the future.

The government has confronted this issue once before, during preliminary planning for the commercial high-level nuclear waste facility in Nevada. That effort led to a recommendation for a Stonehenge-like collection of metal slabs marked in multiple languages and pictograms. Vernon Daub, chief of the Energy Department's Repository Technology Branch at the Carlsbad site, says he worries that a

\title{
Warning away future generations
}

if the significant dose is the one immediately before conception. Very few children were conceived in the few months following the atomic explosions, making statistical comparisons with Gardner's data fruitless. Also, systematic health studies on the bomb survivors and their children began several years after the explosions, meaning that some early leukaemia cases may have been missed.

COMARE says that research must be well co-ordinated to prevent unnecessary intrusion into the lives of radiation workers and their families. The DoH is expected to take the lead in managing the programme, but COMARE will be closely involved, and the Health and Safety Executive (HSE) is expected to pay for much of the research. Although they are outside the remit of its review, COMARE also says that high leukaemia rates in the children of West Cumbrian farmers, steel and chemical workers should also be examined.

DoH and the HSE have already received a number of unsolicited research proposals since the publication of the Gardner report. A spokesman for the HSE says that these will be considered alongside others received after advertisements inviting new research proposals appear in the scientific press.

Peter Aldhous

marker might attract rather than repel future visitors. In addition, he wonders how his group will manage to make any marker long-lived enough to satisfy the regulatory requirements. Daub says that his group is certain to be "conceptually" grappling with "the marker issue" for some time to come. Meanwhile, says Anderson, the group will review past civilizations' efforts to create lasting markers. "The Egyptian pyramids are a good example."

The Department of Energy will probably have a little breathing space before it has to worry about reconstructing the pyramids. Last week, the Environmental Protection Agency proposed that the Waste Isolation Pilot Program (WIPP) be allowed to move into a five-year controlled test phase, during which the facility may ignore some regulations, including the need for permanent exclusion of humans from the site.

If adopted this autumn, the rule will allow the Department of Energy (DOE) to bring radioactive waste to the site from nuclear production facilities around the country during the test period.

The amount of waste shipped would be restricted to less than one half of a per cent of the repository's total planned capacity. It would be monitored over the five-year test period to see if radioactivity leaks from the repository or other problems occur.

Seth Shulman 